\title{
Psammomatous Thoracic spinal meningioma with osseous metaplasia: A very rare case report
}

\author{
Islam KMT ${ }^{1}$, Samadder $\mathrm{S}^{2}$, Ahmed $\mathrm{N}^{3}$, Alam $\mathrm{S}^{4}$, Haque $\mathrm{M}^{5}$, Hossain ATMM ${ }^{6}$
}

Conflict of interest: There is no conflict of interest relevant to this paper to disclose.

Funding Agency : was not funded by any institute or any group.

Contribution of Authors :

Principal Investigator -Dr. K M Tarikul Islam

Data collection- Dr. Soumen Samadder, Dr. Nazmin Ahmed

Manuscript preparation-Dr.Shamsul

Alam, Dr. Moududul Haque

Editorial formatting- Prof. A T M

Mosharef Hossain

Copyright: @2020bang.BJNS published by BSNS. This article is published under the creative commons CC-BY-NC license. This license permits use distribution (https://creativecommons. orgf/licences/by-nc/4-0/)reproduction in any medium, provided the original work is properly cited and is not used for commercial purposes.

Received: 4 February 2019

Accepted: 15 June 2019

\section{Introduction:}

Meningioma together with schwannomas represents majority of intradural extramedullary spinal tumors. Presence of psammoma bodies, gritty foci of calcification are frequently found in spinal meningioma. However, extensive or entire ossification is not that common and when encountered, it

\begin{abstract}
:
Thoracic spinal psammomatous meningioma is a rare subtype of meningioma. Among diverse types of mesenchymal differentiation, osseous metaplasia is found to be still rarer. We are presenting a new case of thoracic psammomatous spinal meningioma with osseous metaplasia in a middle aged female which that gives a sense of cancellous bone in the spinal canal. To conclude, meningiomas with osseous metaplasia are very rare tumors that complicate the surgical removal in certain cases. Ossification, if predicted prior to operation with computed tomography reconstruction, makes planning of removal easier. In our case, maintained cerebrospinal fluid spaces despite firm consistency of tumor made its removal easier once cerebrospinal fluid was drained. We have submitted this article because it is very rare and curable pathology and preoperative diagnosis helps in prevention of neurological injury during its excision.
\end{abstract}

Keywords: Ossified meningioma, psammomatous meningioma, osseous metaplasia.

Bang. J Neurosurgery 2020; 9(2):142-145

1. Dr. K M Tarikul Islam, Associate Professor, Department of Neurosurgery, Bangabandhu Sheikh Mujib Medical University, Dhaka, Bangladesh.

2. Dr. Soumen Samadder, Resident, Department of Neurosurgery, BangabandhuSheikh Mujib Medical University, Dhaka, Bangladesh.

3. Dr. Nazmin Ahmed, Resident, Department of Neurosurgery, BangabandhuSheikh Mujib Medical University, Dhaka, Bangladesh.

3. Dr. Shamsul Alam, Assistant Professor, Department of Neurosurgery, Bangabandhu Sheikh Mujib Medical University, Dhaka , Bangladesh.

5. Dr. Moududul Haque, Associate Professor, Department of Neurosurgery, Bangabandhu Sheikh Mujib Medical University, Dhaka, Bangladesh.

6. Prof. A T M Mosharef Hossain, Professor and Chairman, Department of Neurosurgery, Bangabandhu Sheikh Mujib Medical University, Dhaka, Bangladesh.

Address of Correspondence: Dr. Soumen Samadder, Resident, Department of Neurosurgery, Bangabandhu Sheikh Mujib Medical University, Dhaka, Bangladesh. E-mail:dr.soumen.s@gmail.com 
Aim of this article is to present a new case of ossified spinal meningioma that looks like an elliptical stone in thoracic spinal meningioma.

\section{Case Report}

\section{Clinical history and physical examination}

A 55-years-old normotensive nondiabetic patient female presented with numbness and tingling sensation of both lower limbs for 1year, gradual weakness of both lower limbs for 5 months and burning sensation of both lower limbs for 4 months. Her bladder function is abnormal in the form of urinary retention and bowel function is abnormal in the form of constipation. On query, there was no history of trauma, tuberculosis, UTI, prolong use of steroid etc. Physical examination of spine, there is no visible deformity, no tenderness, no scoliosis, swelling or deformity. Neurological examination of the lower limbs revealed, level of power was MRC grade 1/5 in both sides, jerks were exaggerated, plantar was bilaterally extensor. Pain, touch and temperature sensations were diminished at D10 on right and D8 at left side of trunk.

\section{Laboratory investigations}

Complete blood count revealed red blood cells count, hemoglobin level and white blood cells count were all within a normal range, except high erythrocyte sedimentation rate which was $60 \mathrm{~mm}$ in 1 st hour.

\section{Radiological investigations}

Chest X-ray revealed no pulmonary lesion. MRI of the dorso-lumbar spine with screening of whole spine revealed a hypointense lesion on T1 and T2 image at the level of T1 to T3 and causing compression of the cord anteriorly with widening of posterior cerebrospinal fluid column. After giving contrast, there was mild homoogenous contrast enhancement of the lesion. (Figure 1A, 1B, 1C ) .CT scan of the dorsal region revealed hyperdense calcified lesion at $\mathrm{T} 1$ to T3 (Figure 2A,2B). Postoperative MRI of Dorsolumbar spine revealed no residual tumor. (Figure 4A, 4B)

\section{Management}

Complete T1, T2 and upper part of T3 laminectomy were done. Overlying dura was thick and firm. Midline dural opening was made and dura dissected free from tumor on both sides with difficulty, as it was adherent to the tumor. Around it, tumor was easy to dissect from its ventral aspect, as it was not adherent and firm ventrally. The tumor was firm in consistency, grayish white in color, non succable, non vascular. Tumor was removed in toto and cauterization of dural affiliction was done [Figure 3A,3B ]. Postoperatively, patient had immediate improvement with disappearance of band-like tightening sensation of supra-umbilical area in the abdomen. Patient was in follow-up regularly. Clinically, patient improved from grade ' 1 ' muscle power in lower limbs to grade ' 4 ' and was catheter in situ. MRI of dorso-lumbar spine with screening of whole spine was done and revealed no residual tumor but intensity of cord was persisted. Histipathology reports shows Psammomatous meningioma.
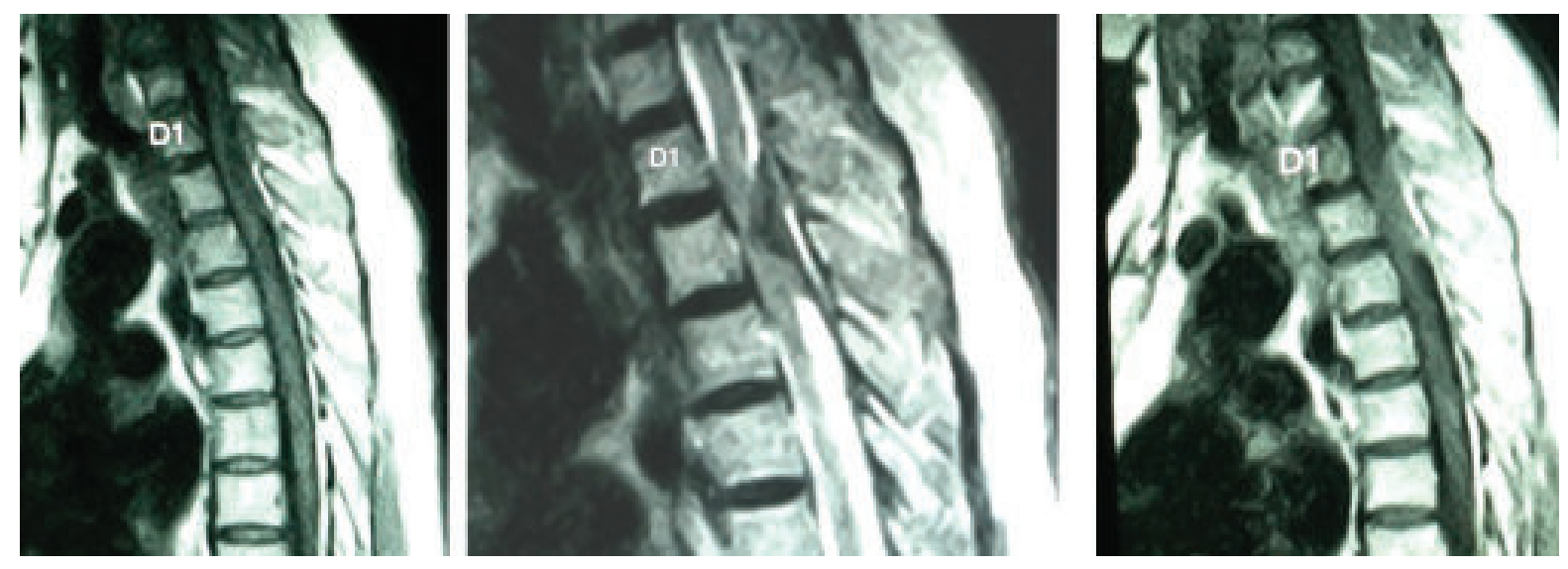

Fig.-1: MRI of dorsolumbar spine with contrast T1WI- hypointense, T2 WI-hypointense, contrast-mild homogenous enhancement $(1 A, 1 B, 1 C)$ 

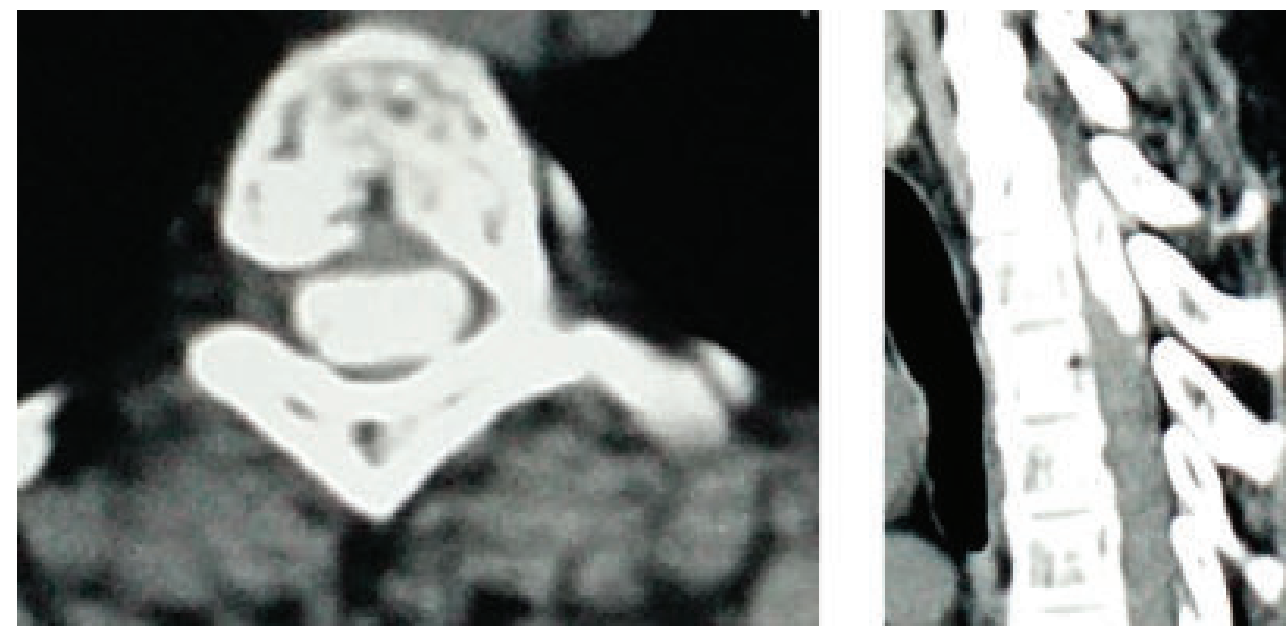

Fig.-2:CT scan of Dorsolumbar spine-hyperdense calcified lesion (2A,2B)
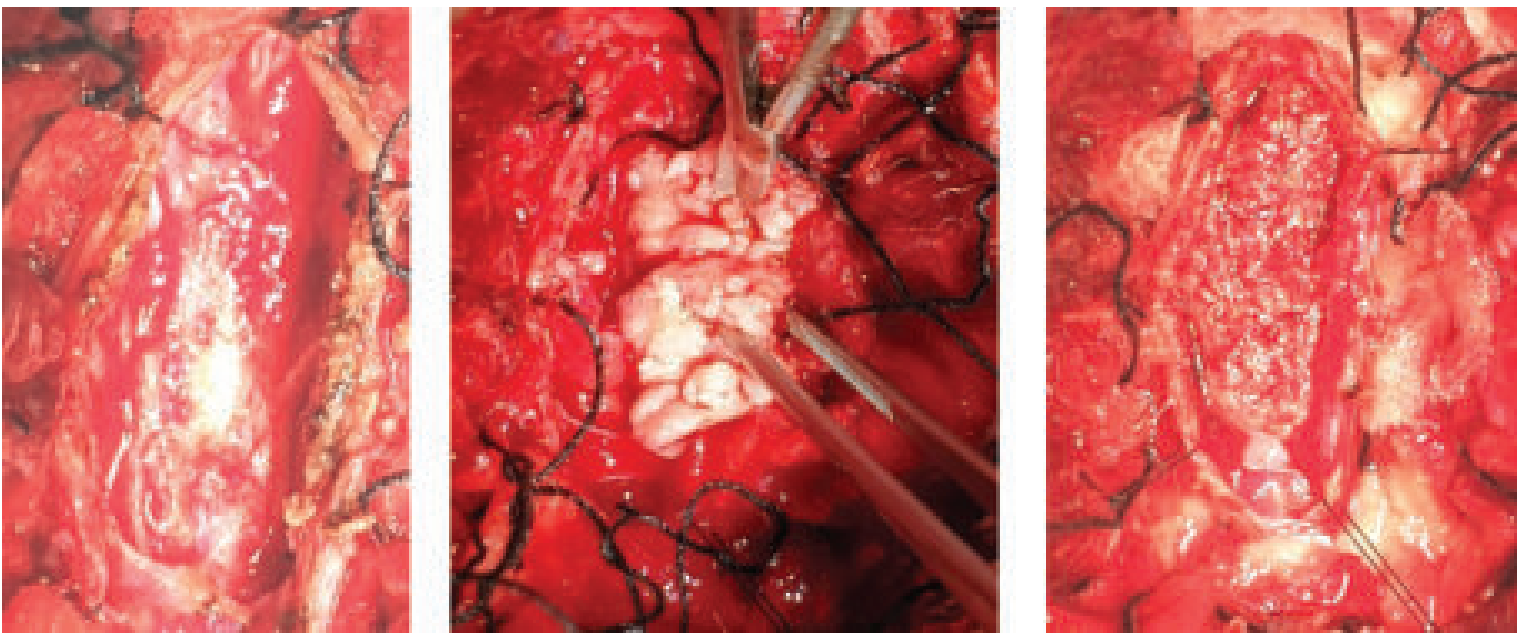

Fig.-3: Intraoperative picture showing dural exposure with hard gritty part of meningioma $(3 A, 3 B, 3 C)$
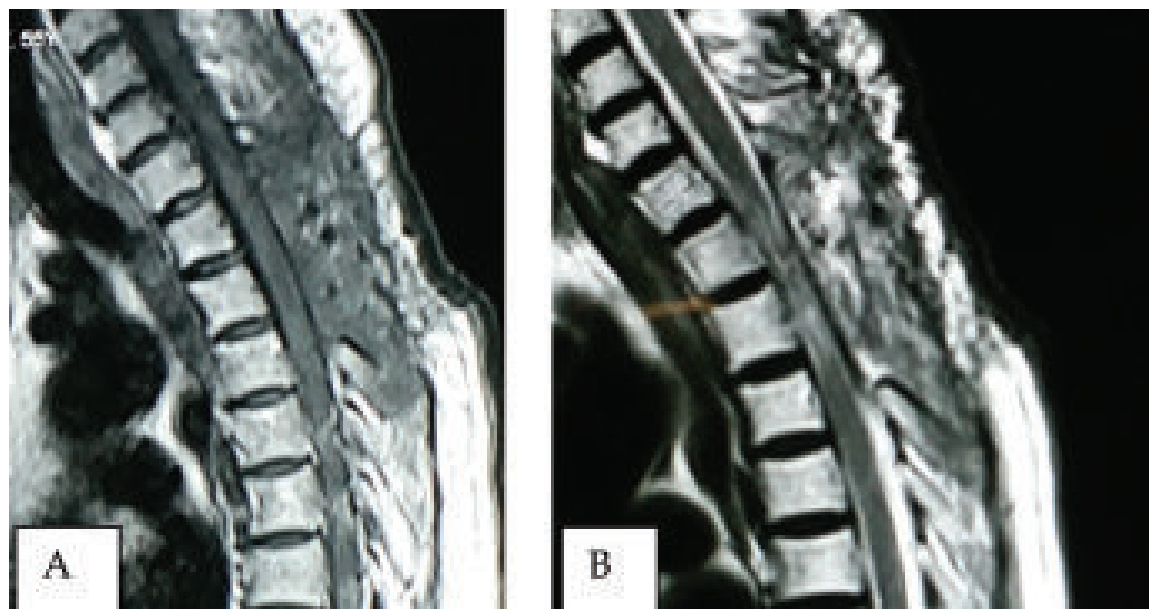

Fig.-4: Postoperative MRI of Dorsolumbar spine T1WI and T2WI (4A, 4B) 

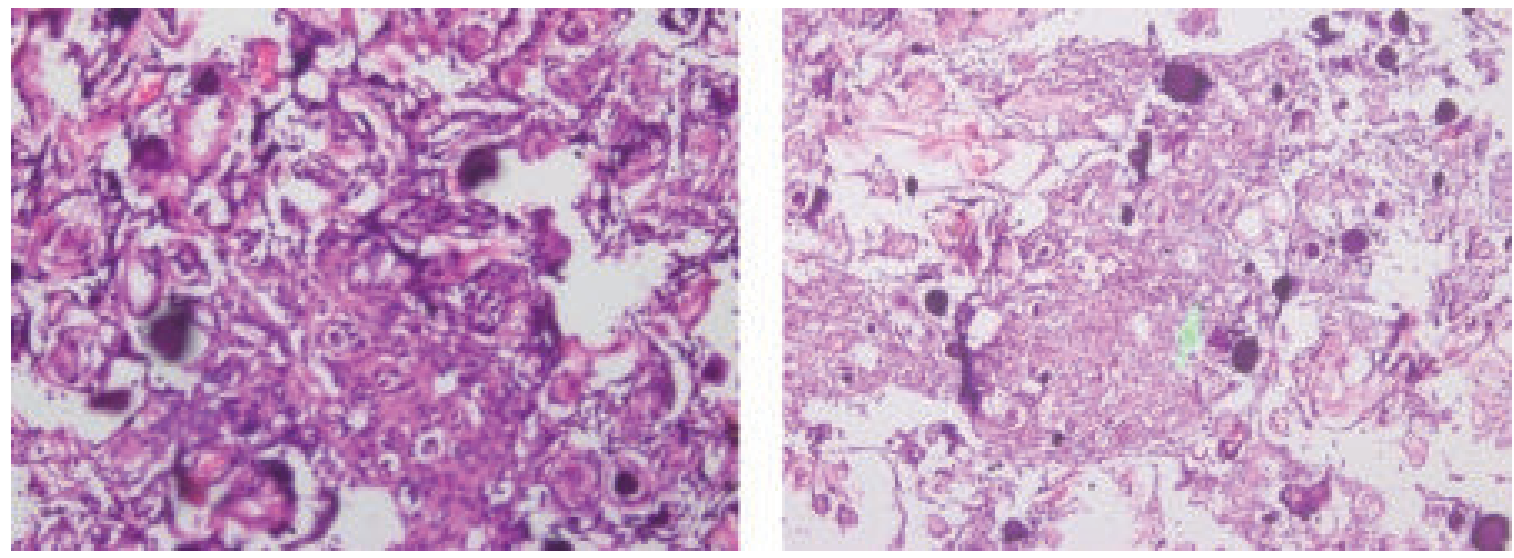

Fig.-5: Histopathology reports showing meningothelial cells with psammoma bodies (5A,5B)

\section{Discussion:}

Ossification in spinal meningioma is a rare event. Most of the cases are in thoracic region, as in our case. Even after reports of certain new cases, there are no definitive figures of its incidence, which is roughly estimated to be $0.7-5.5 \%$ of all spinal tumors. ${ }^{3,4}$ Because of its rigid nature, removal of tumor is associated with complications affecting surgical outcome. But in our case, elliptical shape of the tumor and its non adherence on the spinal cord, made its removal easier, once the superior and inferior poles of the tumor identified and its dissection led to drainage of CSF from the spaces. Different long term outcomes of ossified meningioma surgery have been reported. Roux et al. reported 3 ossified meningioma of 54 spinal meningioma with total removal with good outcome in 2 of these. One removal was subtotal and required a second surgery and radiotherapy. ${ }^{7,8}$ But our case, gross total removal of tumor was done.

\section{Conclusion:}

In conclusion, meningiomas with osseous metaplasia are very rare tumors which complicate surgery in certain cases. Ossification predicted prior to surgery with computed tomography reconstruction makes planning of removal of even hard tumor easier. In our case, maintained CSF spaces made removal easier, once CSF is drained; even without prior computed tomography reconstructive images.

\section{Acknowledgements: None}

Funding Support And Sponsorship: This research did not receive any specific grant from funding agencies in the public, commercial, or not-for-profit sectors.

Conflicts Of Interest: There are no conflicts of interest.

Patient consent: An informed written consent was obtained from each patient.

Ethics approval: There is no ethical issue in this paper.

\section{References:}

1. Louis DN, Scheithauer BW, Budka H. Meningiomas. In: Kleihues P,Cavenee WK, editors. World Health Organization Classification of Tumours, Pathology and Genetics of Tumours of the Nervous System.Lyon: IARC Press; 2000. p. $176-84$.

2. Perry A, Louis DN, Scheithauer BW. Meningiomas. In: Louis DN, Ohgaki H, Wiestler OD, editors. World Health Organization Classification of Tumors of the Central Nervous System. Lyon: IARC Press; 2007. p. 164-72.

3. Liu CL, Lai PL, Jung SM, Liao CC. Thoracic ossified meningioma and osteoporotic burst fracture: Treatment with combined vertebroplasty and laminectomy without instrumentation: Case report. J Neurosurg Spine 2006;4:256-9.

4. Kaufman AB, Dunsmore RH. Clinicopathological considerations in spinal meningeal calcification and ossification. Neurology 1971; 21:1243-8.

5. Rogers L. A spinal meningioma containing bone. Br J Surg 1928; 15:675-7.

6. Colón GP, Ross DA, Hoff JT. Sequential outer table craniotomy a in hyperossified meningioma. Technical note. J Neurosurg 1998; 88:346-8.

7. Mathuriya SN, Vasishta RK, Khandelwal N, Pathak A, Sharma BS, Khosla VK. Calcified falx meningioma. Neurol India 2000; 48:285-7.

8. Roux FX, Nataf F, Pinaudeau M. Intraspinal meningiomas: Review of 54 cases with discussion of poor prognosis factors and modern therapeutic management. Surg Neurol. 1996; 46:458-64. 